\title{
Identification of OPN, TNC and E-selectin as potential recognition proteins in cerebral vasospasm after subarachnoid hemorrhage
}

\author{
Min Jun Wei ${ }^{1}$, Jiu Geng Feng ${ }^{1}$, Zhi Qun Jiang ${ }^{1}$, Chun Hui Zeng ${ }^{1}$, Li Ping Jiang ${ }^{2^{*}}$ and Tao Hong ${ }^{1 *}$
}

\begin{abstract}
Background: Cerebral vasospasm (CVS) after subarachnoid hemorrhage (SAH) is a serious and significant health problem in the worldwide. There are still no effective therapies for treatment of CVS in patients suffering from SAH. Our early studies have demonstrated that the expression of connexin43 (Cx43, a member of gap junctional proteins) in cerebral spastic vessel is significantly up-regulated, and knocking down CX43 with specific siRNA interference can significantly alleviate CVS after SAH. Therefore, Cx43 in cerebral vessel is a potential target in the treatment of CVS. However, Cx43 is widely distributed in many organs, particularly in the heart, and plays an important role in the physiological function. This study is aimed at identify whether OPN, TNC or E-selectin can be used as a target protein to be recognized in spastic cerebral vessels, then we can produce a carrier containing Cx43 siRNA or other inhibitors as a new potential treatment for CVS.

Methods: Twenty eight male Sprague Dawley rats (weighing 300-350 g) were randomly divided into either SAH $(n=16)$ or sham group $(n=12)$. The double hemorrhage model was performed on day 0 and 1 . All animals were sacrificed after performing India ink angiography on day 5. Initially, the expression of E-selectin, TNC and OPN in cerebral arteries, thoracic aorta and abdominal aorta were analyzed respectively by immunohistochemical staining, western blot in both groups. Then, only those with less expression in thoracic aorta, abdominal aorta and normal cerebral arteries, but higher expression in cerebral spastic arteries were further detected in the spinal cord, heart, kidney, liver, spleen, lung, pancreas, mesenteric and pulmonary arteries, retina and brain tissue, respectively.

Results: TNC, OPN and E-selectin were markedly elevated in the spastic cerebral arteries in SAH group but not in control group. The expression of TNC, but not OPN and E-selectin, is abundant in both groups of thoracic aorta and abdominal aorta. Further study demonstrated that expression of OPN, but not E-selecting, in both groups is relatively rich in brain tissue, kidney, pancreas, mesenteric artery, spinal cord and retina, but in heart, liver, lung and pulmonary artery. However, the positive expression of E-selectin was detected in spleen in both groups.

Conclusions: TNC is highly expressed in thoracic aorta and abdominal aorta, so it is unsuitable for being a recognition protein. Although OPN, unlike TNC, does not express much in vascular system, but it expresses in many other organs or tissues. However, E-selecting could be considered as a potential recognition protein because it is not so widely distributed in the organs or tissues detected.
\end{abstract}

Keywords: Cerebral vasospasm, Gap junctional, Cx43, OPN, E-selectin, Targeting protein

\footnotetext{
* Correspondence: Ipjiang@ncu.edu.cn; ht2000@vip.sina.com

${ }^{2}$ Department of Pharmacology, School of Pharmacy, Nanchang University,

461 Bayi Avenue, Nanchang, Jiangxi Province 330006, People's Republic of

China

'Deparment of Neurosurgery, the First Affiliated Hosptial Nanchang

University, Yong wai zheng Street 6, Nanchang, Jiangxi Province 330006,

People's Republic of China
} 


\section{Background}

SAH has a high incidence and poor prognosis. Thirty to sixty percent of these patients may suffer from cerebral vasospasm (CVS), which may result in cerebral ischemia and lead to disability or death [1]. There are a large number of studies relevant to CVS, the technique of microsurgical and vascular surgery were constantly developed and updated. However, the exact pathophysiology process of CVS after SAH is still unclear and therefore there are still no efficient and effective treatment for CVS.

Our early studies have demonstrated that expression of connexin43 (Cx43, a member of gap junctional proteins) in cerebral spastic vessel is significantly upregulated, and knocking down Cx43 with specific siRNA interference can significantly alleviate CVS after SAH. Therefore, $\mathrm{Cx} 43$ in cerebral vessel is a potential target in the treatment of CVS. However, Cx43 is widely distributed in many organs, particularly in the heart, and plays an important role in the physiological function. In order to block the over-expressed $\mathrm{Cx} 43$ in cerebral vascular wall after SAH specifically, we tried to find other targets which only express in the cerebral spastic vessel, but relatively lower in other organs or tissues.

The object of this study is a target protein screen in cerebral spastic artery which can be used as a specific recognition protein and a target to be recognized. In our next study, we can use this specific target to produce a carrier (such as nanoparticle) which contains Cx43 siRNA or other inhibitors as a new potential treatment for CVS.

The blood clots around the cerebral artery can lead to releasing of various vasoactive and pro-inflammatory factors which may cause structural and morphological changes including swelling of smooth muscle cell, shrinkage, hyperplasia and degeneration of vacuolar, necrosis, infiltration of inflammatory cell in the spastic cerebral vascular wall $[2,3]$. During the pathological process of cerebral arteries, media layer (mainly containing SMCs and extracellular matrix) are exposed to the molecular existing in blood, such as neurotransmitter, toxin, drugsand so on [4-7].

Osteopontin (OPN) and Tenascin-C (TNC) secrete extracellular matrix (ECM) glycoproteins, and they perform their functions when they are tied to cell surface receptor, other matrix proteins, cytokines and growth factors. The function of matrix protein is regulating interactions of cell between cell and cell between matrix. During the physiological status, they are barely expressed in mature tissues. However, during the inflammation response, the expression of OPN and TNC are significantly increased. Many studies have showed that matrix protein played an important role in inflammatory response [8-10]. E-selectin is a kind of glycoprotein whose molecular weight is $115 \mathrm{KD}$, which exists in endothelial cells. Pro-inflammatory cytokines such as interleukin, tumor necrosis factor and interferon have stimulatory effects on the synthesis of E-selectin [11]. Studies have revealed that cerebrovascular endothelial cells under normal condition barely have expression of E-selectin. Serum concentration of E-selectin in patients suffering from CVS has no significant change, but increased rapidly in vascular endothelial cells [12]. So, we considered that they might be suitable as target recognition protein.

When CVS occurs after SAH, cerebral vessel will suffer from constant inflammatory response, the drug can easily recognize the elevated expressed target protein and specifically knock down Cx43 of SMCs in spastic cerebral arteries to alleviate CVS after SAH.

\section{Methods}

All procedures were approved by the Animal Ethics Review Committee of Nanchang University and were in accordance with the institution's Guidelines for Animal Experiments.

\section{Animals and experimental groups}

Adult male SD rats (weighing 300-350 g) were provided by the Laboratory Animal Center of Medical College of Nanchang University and housed in an air-filtered unit with free access to food, water is under a 12-h light/dark cycle. The temperature in the feeding room and the operation room was between $22{ }^{\circ} \mathrm{C}$ and $25^{\circ} \mathrm{C}$. The animals were randomly assigned to two groups: (1) sham group $(n=12)$, (2) SAH group $(n=12)$, fresh autologous caudal artery blood $(0.3 \mathrm{ml})$ was injected into the cisterna magna of SD rats.

\section{Induction of experimental SAH}

Rats were anesthetized with an intraperitoneal injection of $10 \%$ chloral hydrate $(300 \mathrm{mg} / \mathrm{kg})$. In the prone position of the rat, the atlanto-occipital membrane was exposed. After the animal was turned into a supine position, fresh autologous non-heparinized blood $(0.3 \mathrm{ml})$ withdrawned from caudal artery. The fixed animal which in a stereotactic frame and a 25-gauge needle was inserted through the atlanto-occipital membrane into the cisterna magna. Then, the $0.1 \mathrm{ml}$ of cerebrospinal fluid (CSF) was slowly withdrew and the autologous blood was injected into the cisterna magna at a speed of $0.15 \mathrm{ml} / \mathrm{min}$. After the injection, the animal was placed at an angle of $30^{\circ}$ in head-down position for about $30 \mathrm{~min}$ in order to facilitate the blood settle around the BA. The same procedure was repeated $24 \mathrm{~h}$ later with a $0.3 \mathrm{ml}$ fresh autologous blood injection. Shan-operated rats underwent the same procedure without the blood injection. 


\section{India ink angiography}

Gelatin-India ink solution was made by dissolving gelatin powder $(7 \mathrm{~g})$ in $100 \mathrm{ml}$ PBS mixed with $100 \mathrm{ml}$ India ink. The ascending aorta was cannulated with a blunted 20-gauge needle attached to flexible plastic tubing, which was connected to a syringe on a micro pump. After an incision made in the right atrium which allowed the outflow of perfusion solutions, $100 \mathrm{ml}$ of PBS, $15 \mathrm{~min}$ of $10 \%$ formalin, and $10 \mathrm{~min}$ of $3.5 \%$ gelatinIndia ink solution were infused through the closed circuit. All perfusates were passed through a $0.2-\mu \mathrm{m}$ pore size filter. The rat was refrigerated at $4{ }^{\circ} \mathrm{C}$ for $24 \mathrm{~h}$ to allow gelatin solidification. The brains were harvested and high-resolution pictures of the circle of Willis and basilar arteries (BAs) were taken with a scale before and after the removal of a subarachnoid clot. The brain was stored in $10 \%$ neutral buffered formalin. An experienced person who was unaware of the treatment group measured the smallest lumen diameter of BA, used Image J software for three times and determined a mean value per segment.

\section{H\&E staining}

After five days, the second hemorrhage rat was perfused with PBS. The brainstem containing BA was immediately removed and post-fixed in the $4 \%$ paraformaldehyde (PFA) $100 \mathrm{ml}$ for $24 \mathrm{~h}$. The entire length of BA was divided into proximal, middle, and distal. After it dissected, the middle section was deparaffinized, hydrated, washed, and stained with Hematoxy-lin-eosin ( $\mathrm{H}$ \& E) staining.

\section{Immunohistochemical staining}

Transections of rats organs were processed into paraffin blocks, and were cut into $10-\mu \mathrm{m}$ slices. After deparaffinized, the slices were heated and boiled for $15 \mathrm{~min}$ in citrate buffer solution $(0.01 \mathrm{M}, \mathrm{PH}=6.0)$ for retrieval antigen. Each section was treated with 3 \% hydrogen peroxide for $20 \mathrm{~min}$ at room temperature and was used to diminish nonspecific staining. After rinsing with PBS, the slices were blocked with $5 \%$ normal goat serum in PBS (0.01 M, PH = 7.4) for $20 \mathrm{~min}$ at room temperature. The slices were incubated overnight at $4{ }^{\circ} \mathrm{C}$ with the Rabbit Anti-osteopontin antibody (bs-0019R, Bioss Biotechnology corporation, Beijing, China), Rabbit AntiTenascin C antibody (bs-1039R, Bioss Biotechnology corporation, Beijing, China), and Rabbit Anti-E-Selectin antibody (bs-1273R, Bioss Biotechnology corporation, Beijing, China). After rinsing with PBS, the specimens were incubated with biotinylated secondary antibody (ZSGB-BIO, Beijing, China) at room temperature for $20 \mathrm{~min}$ and then re-incubated with horseradish peroxidase-labeled streptavidin for $20 \mathrm{~min}$. The immunoreactivity was revealed by 3'diaminobenzidine (DAB) solution and counterstained with hematoxylin. The primary antibody was omitted for the negative control.

\section{Western blotting}

Rats were killed under the deep anesthesia after five days in the second hemorrhage. The BA, brain tissue, heart, liver, kidney, lung, spleen, pancreas, spinal cord, thoracic aorta, abdominal aorta, pulmonary artery and mesenteric artery were isolated. The specimens were homogenized in ice-cold extract buffer $(\mathrm{PH}=7.4)$ and centrifuged at $20,000 \mathrm{rpm}$ for $20 \mathrm{~min}$ at $4{ }^{\circ} \mathrm{C}$. The protein concentration was determined by using a BCA kit (Thermo Fisher Scientific, USA). Equal amounts of protein samples $(10 \mu \mathrm{g})$ were loaded on a tris glycine gel, separated by $12 \%$ SDS-PAGE, electrophoresed, and transferred to a polyvinylidencedifluoride (PVDF) membrane. Then, the membrane was blocked with $5 \%$ skimmed milk for $2 \mathrm{~h}$ at room temperature, incubated overnight at $4{ }^{\circ} \mathrm{C}$ with the Rabbit Anti-osteopontin antibody (bs-0019R, 1:200, Bioss Biotechnology corporation, Beijing, China), Rabbit Anti-Tenascin C antibody (bs-1039R, 1:200, Bioss Biotechnology corporation, Beijing, China), and Rabbit Anti-E-selectin antibody (bs-1273R, 1:200, Bioss Biotechnology corporation, Beijing, China). GAPDH (1:1000, Cell Signaling Technology, USA) was blotted on the same membranes as a loading control. The membrane was then incubated with goat anti-rabbit horseradish peroxidase-conjugated secondary antibodies (1:4000, ZSGB-BIO, Beijing, China) for $2 \mathrm{~h}$ at room temperature. The immunoreactive bands were visualized using an enhanced chemiluminescence method and quantified with Image J software (NIH). Results were expressed as a relative density to GAPDH.

\section{Statistical analysis}

The SPSS software package v 19.0 was used for all analyses. Data expressed as mean \pm standard deviation (SD). The death rates were used in the chi-square test for contrast. Differences between these means were evaluated by the one-way analysis of variance (ANOVA) followed by the Student-Newman-Keuls (SNK) test for multiple comparisons. " $P<0.05$ were considered statistically significant.

\section{Results \\ CVS situation after SAH Motality}

The mortality rate of SD rats was $25 \%$ (4 of 16) in SAH group, none in sham group (0 in 12). There was no significant difference were observed in the physiological parameters (body weight, body temperature, pulse, blood pressure and breathing) in the present study between $\mathrm{SAH}$ and sham-operated rats or within the groups over time. 

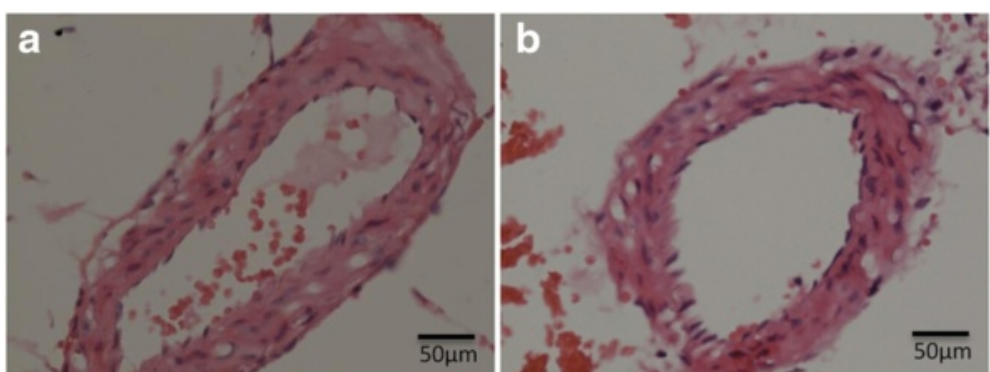

Fig. 1 Morphological changes of BA after SAH in H\&E staining. a The sham group $(n=12)$ showed no appearance of vasospasm. $\mathbf{b}$ In SAH group $(n=12)$, morphological changes of BA include narrowing of vessels, increased thickness of vascular wall, distorted of vascular endothelial cells and crimped of internal elastic layer. scale bars $=50 \mu \mathrm{m}$

\section{CVS after SAH in H\&E staining}

Morphological changes of BA in $\mathrm{H}$ \& $\mathrm{E}$ staining were shown in Fig. 1. The wall of normal control BA was thinner, full of intima, uniform distribution of endothelial cells with smooth internal elastic lamina and distributed with uniform and compact smooth muscle cells.
BA showed obvious contraction in SAH but not in the sham group. And the wall of BA in SAH group became thicker. Vascular endothelial cell nucleus chromatin of cerebral vessel was aggregated, and internal elastic layer was significantly corrugated. The distribution of cerebrovascular SMCs became sparse, and surrounded by red-

\section{a}

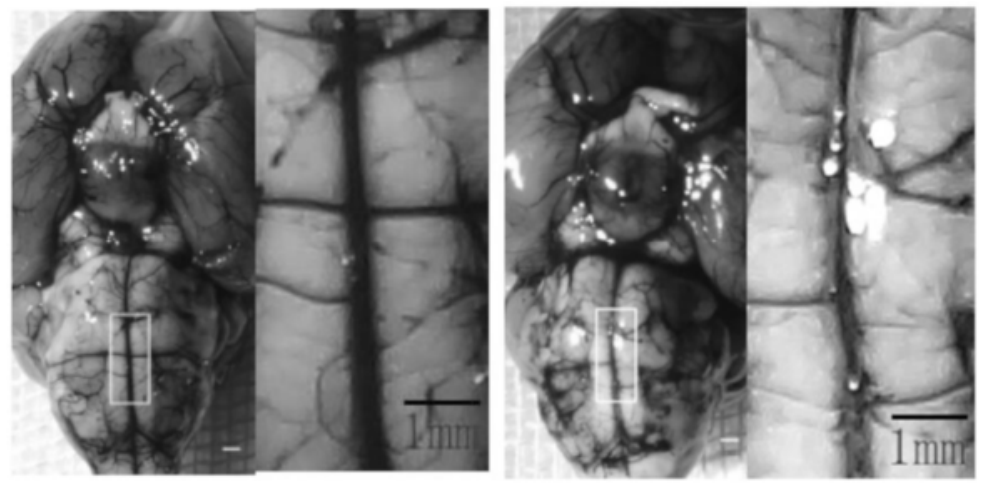

b

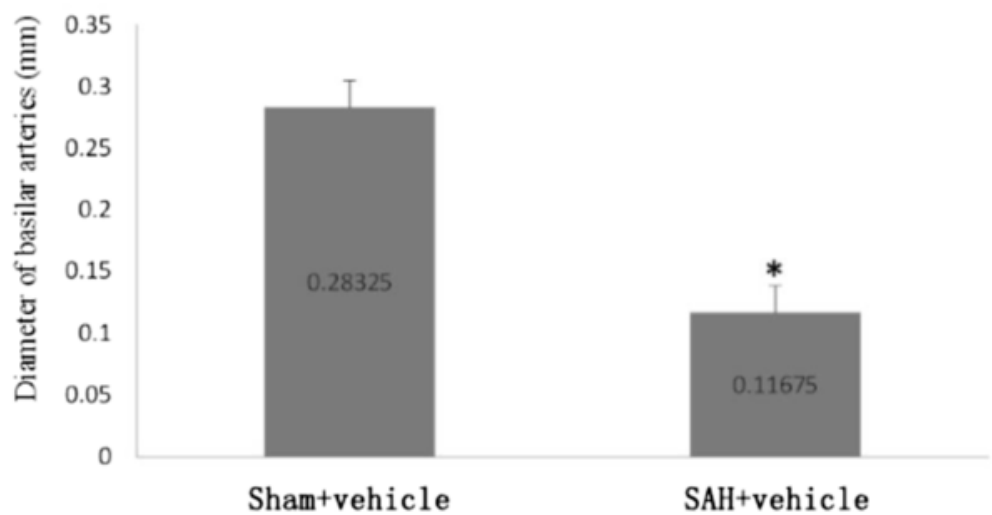

Fig. 2 Effects of a cisternal injection of blood on the diameter of basilar arteries in rats. a Representative angiograms of India ink; b Diameter of BA on day 5 after second hemorrhage in both groups. Histograms of the diameter of BA showed significant decrease in SAH group compared with that in sham group. Data are the means $\pm \operatorname{SEM}(n=12) .{ }^{*} P<0.05$ versus normal BA 


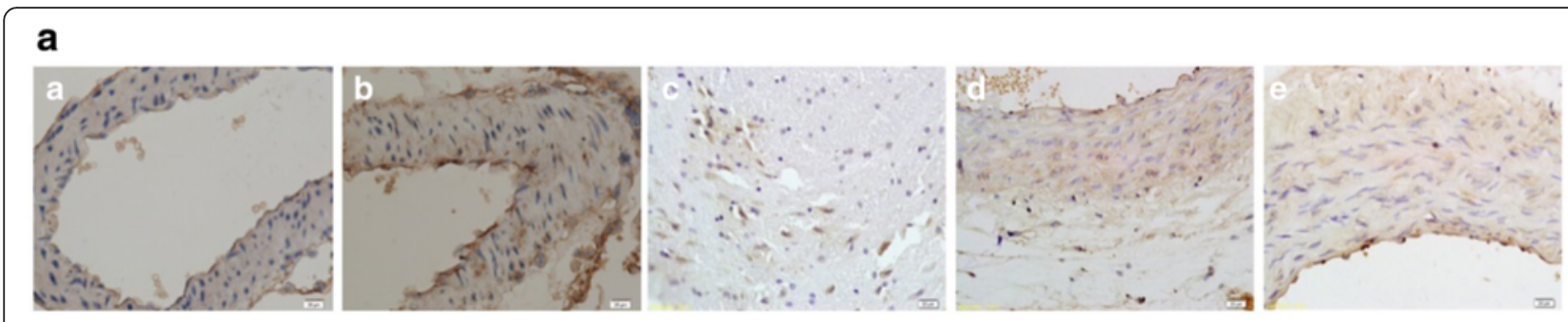

\section{b}
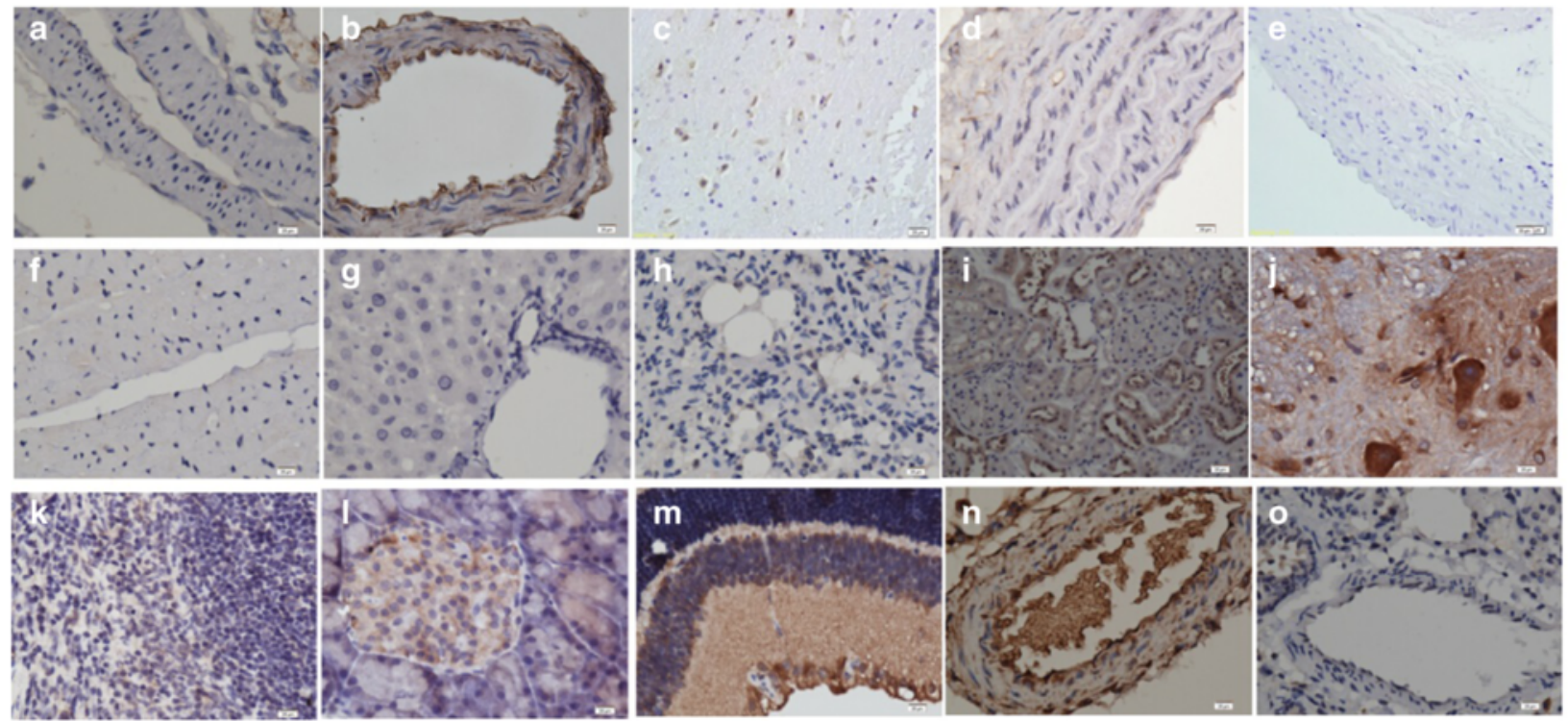

C
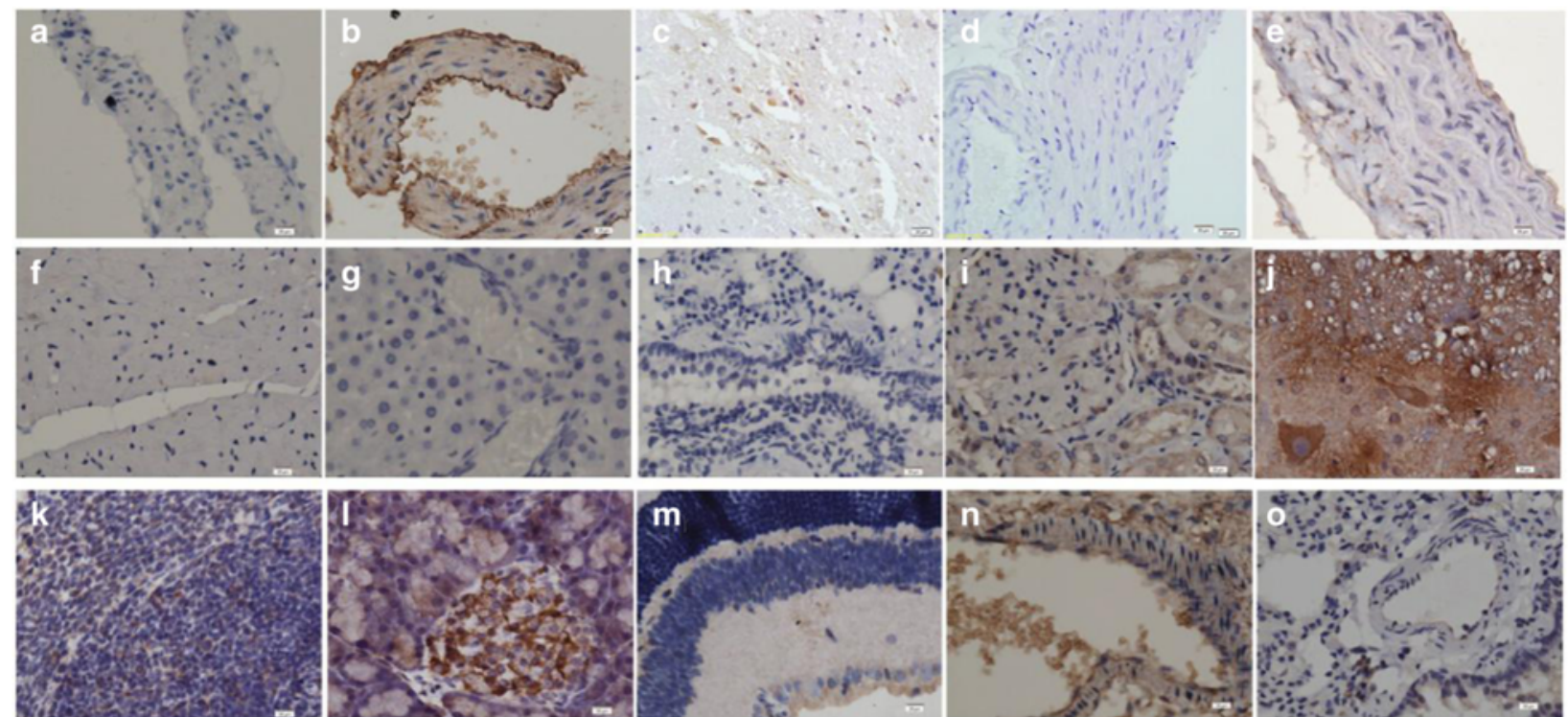

Fig. 3 Representative immunohistochemical images of the expression of OPN, TNC and E-selectin in different tissues. (a), (b) and (c) respectively represented TNC, OPN and E-selectin were expressed in different tissues and organs. In the pictures, (a) to (o) represented: (a) normal cerebral vessels; (b) cerebral vessels on day 5 post-SAH; (c) brain tissue; $(d)$ thoracic aorta; (e) abdominal aorta; $(f)$ heart; $(g)$ liver; $(h)$ lungs; $(i)$ kidney; $(j)$ spinal cord; $(k)$ spleen; ( () pancreas; $(m)$ retina; $(n)$ mesenteric artery and (o) pulmonary artery. It showed that TNC had a wealth of expression in thoracic aorta and abdominal aorta, however, low level of expression in spastic cerebral vessels. OPN in brain tissue, spinal cord, kidney, pancreas, mesenteric artery and retina had obviously positive expression, this change also happened in spastic cerebral vessels after SAH. E-selectin and OPN had a similar region of expression, but the difference was that E-selectin had a higher expression in spleen. scale bars $=20 \mu \mathrm{m}$ 

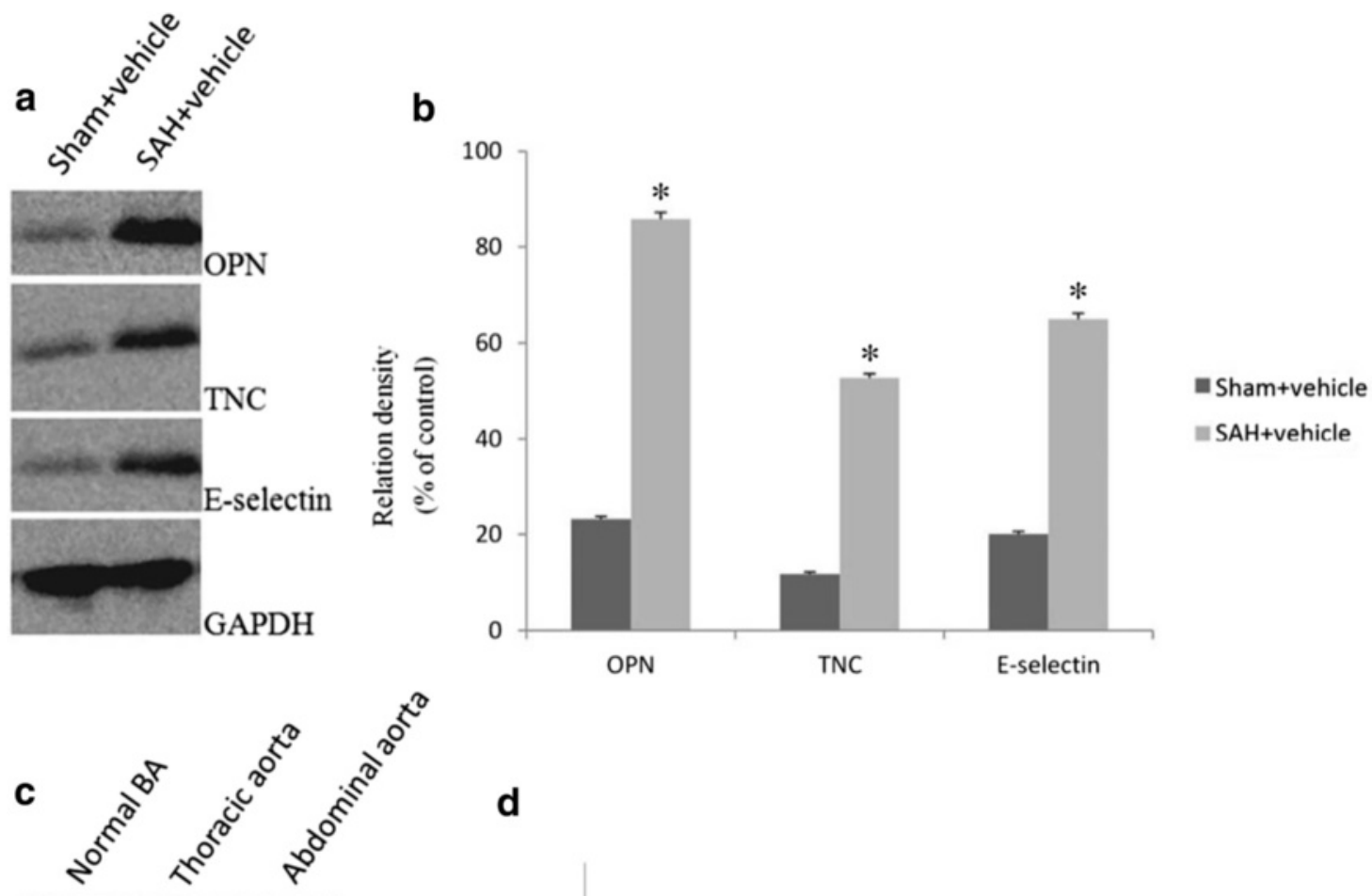

\section{d}
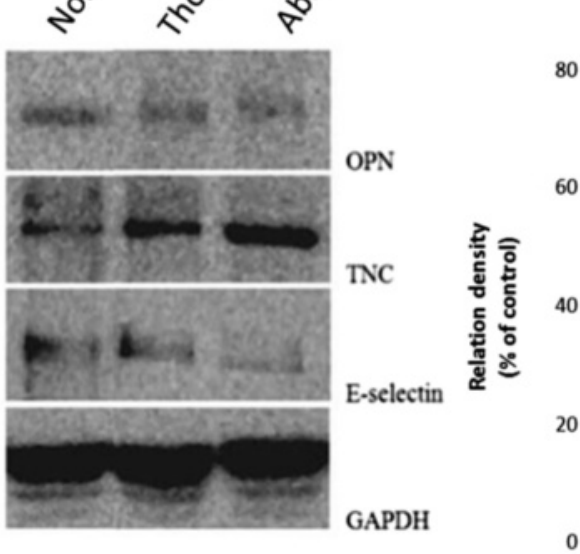

GAPDH

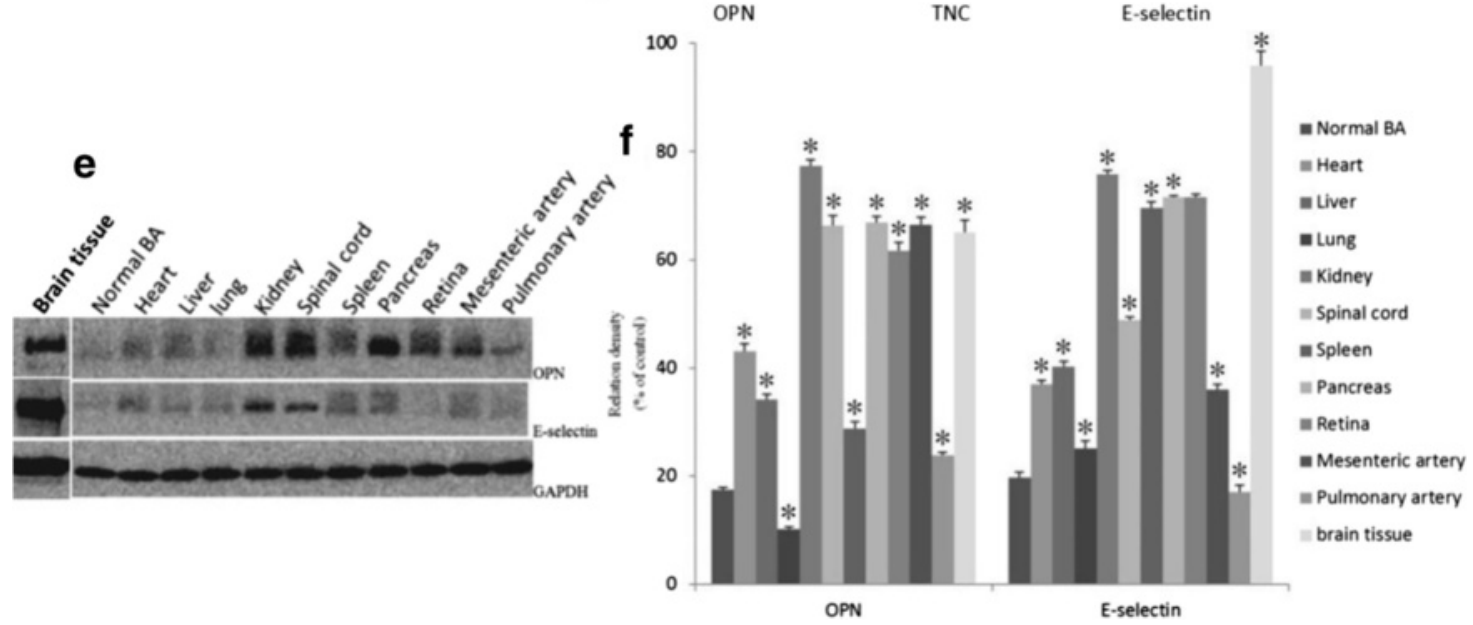

Fig. 4 (See legend on next page.) 
(See figure on previous page.)

Fig. 4 Expressions of OPN, TNC and E-selectin in BA and other tissues. a represented the expression of OPN, TNC and E-selectin in BA measured by western blot. In sham group ( $n=12)$, SAH group $(n=12)$, $\mathbf{c}$ and e showed elevated expression of OPN, TNC and E-selectin in other tissues and organs of the body. $\mathbf{b}, \mathbf{d}$ and $\mathbf{f}$ were quantitative analysis of them. $\mathbf{a}$ and $\mathbf{b}$ showed that all of them had markedly increased in SMCs of spastic cerebral arteries compared with control animals. $\mathbf{c}$ and $\mathbf{d}$ described that TNC had a high expression in thoracic aorta and abdominal aorta. e and f showed that the level of OPN and E-selectin expression were significantly increased in brain tissue, spinal cord, kidney, pancreas, mesenteric artery and retina, on the other hand, E-selectin had a high expression in spleen. Data are the means \pm SEM $(n=12) .{ }^{*} P<0.05$ versus normal BA

stained tissue. The nucleus of cerebrovascular SMCs were elongated, and internal elastic lamina were suffered from edema and deterioration.

\section{India ink angiography}

India ink angiography after SAH showed the diameter of BA in Fig. 2. The results suggested that contrast with sham groups, the diameter of BA in SAH group was significantly reduced.

\section{OPN, TNC, E-selectin expressions different tissues after $\mathrm{SAH}$}

Expression of OPN, TNC and E-selectin in tissues distribution by immunohistochemical method

The expression of OPN, TNC and E-selectin in tissues and organs were investigated by immunohistochemical method showed in Fig. 3. These results indicated that TNC had a wealth of expression in thoracic aorta and abdominal aorta, however, low level of expression in spastic cerebral vessel. It can not be considered as target recognition protein we need. OPN in some tissues and organs (brain tissue, spinal cord, kidney, pancreas, mesenteric artery and retina) had obviously elevated expression, however, the expression of which in spastic cerebral vessel after SAH was dramatically increased compared with that in sham group. The distribution of expression of E-selectin in organs and tissues was similar to OPN, but the level of expression of E-selectin was lower than OPN, except for spleen.

\section{Expression of OPN, TNC and E-selectin by western blot}

The expression of OPN, TNC and E-selectin were also investigated by western blot showed in Fig. 4. From the chart, we can see that TNC in thoracic aorta and abdominal aorta had obvious expression, and it was consistent with the results of immunohistochemical method. There were obviously postive expression of OPN but Eselectin in some organs and tissues (brain tissue, spinal cord, kidney, pancreas, mesenteric artery and retina), however, the expression of OPN was observably elevated in spastic cerebral vessels after SAH. On the other hand, the positive expression of E-selectin was detected in spleen.

\section{Discussion}

Currently, there are many kinds of treatments for CVS after SAH [13-21]. However, these methods can only reduce a part of occurrence of CVS [22]. Our previous studies have showed that specific knocking down $\mathrm{Cx} 43$ in spastic cerebral arteries with specific siRNA interference can significantly alleviate CVS after SAH. On the basis of this, we mainly aimed at screening of a specific high expression of protein as a recognition target in spastic cerebral vessels, and achieve the goal of targeted therapy for CVS.

Some studies have showed that the pathological process of CVS after SAH was relevant to cerebrovascular inflammatory response [3, 23]. OPN and TNC are mainly located in cytoplasm and extracellular matrix [8]. Studies indicated that the expression of these proteins elevated during inflammation. E-selectin is mainly located in vascular endothelial cells, and the expression of which can be obviously induced by inflammatory cytokine especially in cerebrovascular endothelial cells. However, the serum concentration of which will not upregulate at all [11].

From the results of this study, we confirmed that the expression of OPN, TNC and E-selectin in normal cerebral vessel are in low level. However, the expression of them markedly increased in spastic cerebral vessels after SAH. They were in accord with the basic requirement of being target recognition protein.

For the next study, we found that the expression of TNC, but not OPN and E-selectin, extremely upregulated in aorta system (such as thoracic and abdominal aorta). So we considered that TNC might not be suitable as a target recognition protein. And the study of it was stopped here.

Moreover, we have found that the expression of OPN and E-selectin in some organs and tissues (including brain tissue, kidney, pancreas, intimal layer of mesenteric artery, spinal cord and retina) were elevated. Otherwise, the positive expression of E-selectin but OPN was detected in spleen, however, there are still not too many literatures show that Cx43 takes part in physiological function of spleen. Therefore, we might choose Eselectin as the best target recognition protein of these proteins.

As we all know, cerebrovascular smooth muscle cells (SMCs) are located in media layer of cerebral vessel wall. In order to alleviate continuous contraction of SMCs in cerebral vessels, the drug (carrying Cx43 siRNA or other inhibitors) injected into blood needs to cross the intimal 
layer. Under normal condition, vascular endothelial cells are tightly connected with each other, so drugs can not easily pass though the vascular endothelial cells. Fortunately, when CVS occurs after SAH, cerebrovascular endothelial cells and inner elastic layers are suffered from obvious shrinkage or even necrosis [24]. The tight junctions of cerebral vascular endothelial cells are separated. That media layer of spastic cerebral vessels can be exposed to the drug in blood. Meanwhile, highly expressed target protein can be recognized by the drug in blood, and Cx43 can be specific knocked down in spastic cerebral vessel without affecting other organs and tissues.

Some literatures find that kidney has a wealth expression of connexin, and they play a very important role in regulating physiological function of kidney [25]. The connexin is extremely important to maintain the physiological function of pancreatic islet cells [26]. Vessels of these organs and tissues have normal structure and function. The tight junction of vascular endothelial cells can effectively prevent the drug from invading into organs and tissues. In consequence, specifically recognized the target protein in spastic cerebral vessels can be considered to be a potential useful method in treatment of CVS after SAH. And Eselectin may be the best one of these proteins as target recognition protein.

\section{Conclusion}

The results of the this study showed that E-selectin may be considered as target recognition proteins, however, OPN and TNC may not be suitable as target recognition protein. After we built the vehicle carrying Cx43 siRNA or other inhibitors, further research of E-selectin will be carried out.

\section{Abbreviations}

CVS, cerebral vasospasm; ECM, extracellular matrix; OPN, osteopontin; PBS, phosphate-buffered saline; $\mathrm{SAH}$, subarachnoid hemorrhage; TNC, tenascin-C.

\section{Acknowledgements}

This study was supported by the NNSF: Gap junction protein phosphorylation in the study of cerebral vasospasm (Grant Number: 81060099).

\section{Authors' contributions}

MJW performed the experiments, acquired the data, analyzed the data and wrote the manuscript. TH conceived and designed the study, LPJ interpreted the data. JGF critically revised the manuscript, ZQJ read and approved the manuscript, $\mathrm{CHZ}$ check the pictures of the article. All authors read and approved the final manuscript.

\section{Competing interests}

The authors declare that they have no competing interests.

Received: 31 May 2015 Accepted: 18 May 2016

Published online: 18 June 2016

\section{References}

1. Mayberg MR. Cerebral vasospasm. Neurosurg Clin N Am. 1998;9(3):615-27.
2. Vatter H, Konczalla J, Seifert V. Endothelin related pathophysiology in cerebral vasospasm: what happens to the cerebral vessels? Acta Neurochir Suppl. 2011;110(Pt 1):177-80.

3. Hansen-Schwartz J. Cerebral vasospasm: a consideration of the various cellular mechanisms involved in the pathophysiology. Neurocrit Care. 2004; 1(2):235-46.

4. Park KW, Metais C, Dai HB, Comunale ME, Sellke FW. Microvascular endothelial dysfunction and its mechanism in a rat model of subarachnoid hemorrhage. Anesth Analg. 2001;92(4):990-6.

5. Ishiguro M, Puryear CB, Bisson E, Saundry CM, Nathan DJ, Russell SR, Wellman GC. Enhanced myogenic tone in cerebral arteries from a rabbit model of subarachnoid hemorrhage. Am J Physiol Heart Circ Physiol. 2002; 283(6):H2217-25.

6. Iuliano BA, Pluta RM, Jung $C$, Oldfield EH. Endothelial dysfunction in a primate model of cerebral vasospasm. J Neurosurg. 2004;100(2):287-94.

7. Zhou C, Yamaguchi M, Colohan AR, Zhang JH. Role of p53 and apoptosis in cerebral vasospasm after experimental subarachnoid hemorrhage. J Cereb Blood Flow Metab. 2005;25(5):572-82.

8. Wang KX, Denhardt DT. Osteopontin: role in immune regulation and stress responses. Cytokine Growth Factor Rev. 2008;19(5-6):333-45.

9. Suzuki H, Shiba M, Fujimoto M, Kawamura K, Nanpei M, Tekeuchi E, Taki W. Matricellular protein: a new player in cerebral vasospasm following subarachnoid hemorrhage. Acta Neurochir Suppl. 2013;115:213-8.

10. Suzuki H, Hasegawa Y, Chen W, Kanamaru K, Zhang JH. Recombinant osteopontin in cerebral vasospasm after subarachnoid hemorrhage. Ann Neurol. 2010;68(5):650-60.

11. Tsao KC, Chang PY, Li CC, Wu TL, Sun CF, Wu JT. Development of a microplate ELISA for circulating E-selectin: assay characterization, comparison with a commercial kit, wand establishment of normal reference values. J Clin Lab Anal. 2003;17(3):97-101.

12. Frijns CJ, Rinkel GJ, Castigliego D, Van Gijn J, Sixma JJ, Fijnheer R. Endothelial cell activation after subarachnoid hemorrhage. Neurosurgery. 2002;50(6):1223-9. discussion 1229-1230.

13. Amin-Hanjani S, Ogilvy CS, Barker 2nd FG. Does intracisternal thrombolysis prevent vasospasm after aneurysmal subarachnoid hemorrhage? A metaanalysis. Neurosurgery. 2004;54(2):326-34. discussion 334-325.

14. Kawamoto S, Tsutsumi K, Yoshikawa G, Shinozaki MH, Yako K, Nagata K, Ueki $K$. Effectiveness of the head-shaking method combined with cisternal irrigation with urokinase in preventing cerebral vasospasm after subarachnoid hemorrhage. J Neurosurg. 2004;100(2):236-43.

15. Findlay JM, Kassell NF, Weir BK, Haley Jr EC, Kongable G, Germanson T, et al. A randomized trial of intraoperative, intracisternal tissue plasminogen activator for the prevention of vasospasm. Neurosurgery. 1995;37(1):168-76. discussion 177-168.

16. Onal MB, Solmaz I, Civelek E, Kircelli A, Tehli O, Izci Y, Gonul E. Comparison of intrathecal dotarizine and nimodipine treatments in cerebral vasospasm after subarachnoid hemorrhage: an experimental study in rabbits. Acta Neurochir Suppl. 2011;110(Pt 2):55-60.

17. van den Bergh WM, Algra A, van Kooten F, Dirven CM, van Gijn J, Vermeulen $M$, et al. Group MS. Magnesium sulfate in aneurysmal subarachnoid hemorrhage: a randomized controlled trial. Stroke. 2005;36(5):1011-5.

18. Provencio JJ, Vora N. Subarachnoid hemorrhage and inflammation: bench to bedside and back. Semin Neurol. 2005;25(4):435-44

19. Chang CZ, Wu SC, Kwan AL, Lin CL. Preconditioning with pitavastatin, an HMG-CoA reductase inhibitor, attenuates $\mathrm{C}$-Jun $\mathrm{N}$-terminal kinase activation in experimental subarachnoid hemorrhage-induced apoptosis. Acta Neurochir (Wien). 2015;157(6):1031-41.

20. Tseng MY, Czosnyka M, Richards H, Pickard JD, Kirkpatrick PJ. Effects of acute treatment with pravastatin on cerebral vasospasm, autoregulation, and delayed ischemic deficits after aneurysmal subarachnoid hemorrhage: a phase II randomized placebo-controlled trial. Stroke. 2005;36(8):1627-32.

21. Lynch JR, Wang H, McGirt MJ, Floyd J, Friedman AH, Coon AL, Laskowitz DT. Simvastatin reduces vasospasm after aneurysmal subarachnoid hemorrhage: results of a pilot randomized clinical trial. Stroke. 2005;36(9):2024-6.

22. Chen S, Wu H, Tang J, Zhang J, Zhang JH. Neurovascular events after subarachnoid hemorrhage: focusing on subcellular organelles. Acta Neurochir Suppl. 2015;120:39-46.

23. Muroi C, Mink S, Seule M, Bellut D, Fandino J, Keller E. Monitoring of the inflammatory response after aneurysmal subarachnoid haemorrhage in the clinical setting: review of literature and report of preliminary clinical experience. Acta Neurochir Suppl. 2011;110(Pt 1):191-6. 
24. Yilmaz A, Aydin MD, Kanat A, Musluman AM, Altas S, Aydin Y, Gursan N. The effect of choroidal artery vasospasm on choroid plexus injury in subarachnoid hemorrhage: experimental study. Turk Neurosurg. 2011:21(4):477-82.

25. Hanner F, Sorensen CM, Holstein-Rathlou NH, Peti-Peterdi J. Connexins and the kidney. Am J Physiol Regul Integr Comp Physiol. 2010;298(5):R1 143-55

26. Farnsworth NL, Benninger RK. New insights into the role of connexins in pancreatic islet function and diabetes. FEBS Lett. 2014;588(8):1278-87.

Submit your next manuscript to BioMed Central and we will help you at every step:

- We accept pre-submission inquiries

- Our selector tool helps you to find the most relevant journal

- We provide round the clock customer support

- Convenient online submission

- Thorough peer review

- Inclusion in PubMed and all major indexing services

- Maximum visibility for your research

Submit your manuscript at www.biomedcentral.com/submit 